Proc. Indian Acad. Sci., Vol. 87 A (E \& P Sciences-4), No 11, November 1978, pp. 225-230, (C) printed in India

\title{
On the origin of ringing irregularities-A meteor hypothesis
}

\author{
M R DESHPANDE, HARI OM VATS and A I TRIVEDI \\ Physical Research Laboratory, Ahmedabad 380009
}

MS received 16 May 1978; revised 21 August 1976

\begin{abstract}
Isolated ionospheric irregularities produce oscillating (ringing) diffraction patterns on the ground. Typical physical properties such as density, size, etc. of these irregularities have been estimated using the characteristics of these diffraction patterns. These physical properties agree well with those of meteor trail ionisation. In addition it has been found that most of the ringing irregularities occur on meteor shower days. Further, investigations of diurnal and seasonal patterns of tinging irregularities and meteor showers suggest that the meteor showers are the most likely cause of ringing irregularities. Hence it is hypothesised that the ringing irregularities are caused by meteor showers. It is to be noted that the current observations of isolated ionespheric irregularities are near the equator (around $9^{\circ} \mathrm{N}$ latitude) and they fill an observational gap in meteor showers which existed at equatorial latitudes. It has been observed that there is no marked difference in diurnal variation of meteor showers over the globe whereas there exists a strong latitudinal variation of the meteor showers.
\end{abstract}

Keywords. Ringing irregularity; ionospheric irregularity; meteor hypothesis.

\section{Introduction}

In recent years the study of radio star and satellite signal scintillations has brought to light a phenomenon that is referred to as quasi-periodic scintillation (Ireland and Preddy 1967; Elkins and Slack 1969; Heron 1976; Davies and Whitehead 1977). This form of scintillation is usually characterised by a broad minima in the received signal strength which is flanked on both sides by a damped oscillatory variation of the signal level (figure 1a). The phenomenon is generally attributed to the drifting of an orderly diffraction pattern generated by an isolated (ringing) irregularity across the radio line of sight (Titheridge 1971; Davies and Whitehead 1977; Elkins and Slack 1969). These irregularities hereafter will be referred to as Ringing Irregularities (RI).

Model calculations of these diffraction patterns have shown that in many cases the observed 'ringing' patterns may be explained by considering diffraction by symmetrical Gaussian irregularities of appropriate cross-sectional dimensions $(d)$ and electron density enhancements $(\triangle N)$. In rare instances, however, more complex models such as asymmetric or perturbed Gaussian distributions of $\triangle N$ have also been proposed (Heron 1976; Trivedi et al 1978) to explain complex diffraction patterns.

Thus while there is a consensus of opinion about the cause of quasi-periodic scintillations, little is known so far about the origin of the isolated ' ringing' irregular- 


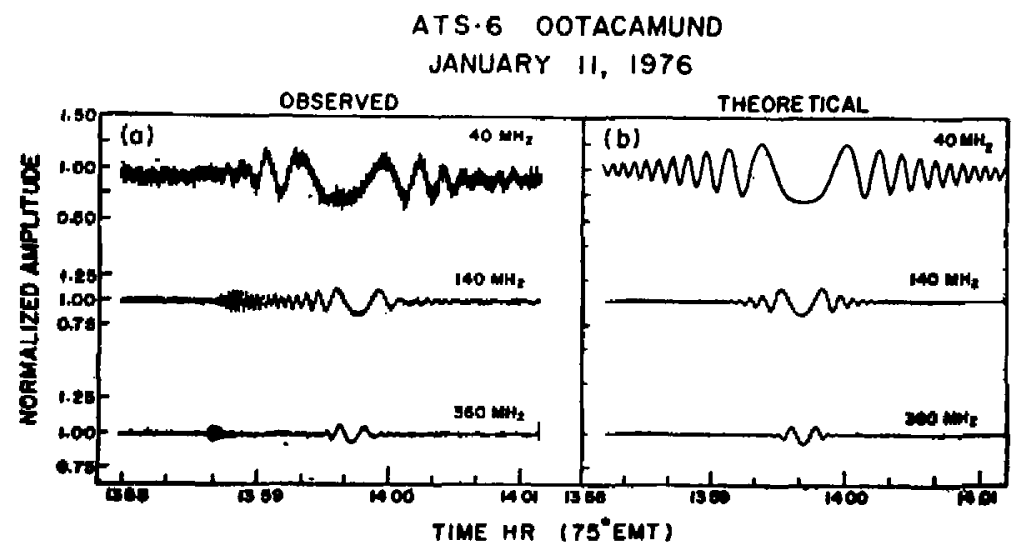

Figure 1. Observed and theoretical diffraction patterns caused by an isolated irregularity.

ities responsible for such events. One possible mechanism for generation of these ringing irregularities may be meteoric ionisation, particularly in the case of irregularities located at $E$ layer heights. The present paper examines this hypothesis.

The results are encouraging in that they show a fair correspondence between the statistics of meteor activity and the occurrence of ringing irregularities. The scale sizes and the strength of the irregularities seem to show agreement with those of meteor trails. In $\S 2$ and 3 physical properties of these irregularities and those of meteor trails are discussed respectively. In $\S 4$ comparison of experimental results of $\mathrm{RI}$ and meteor trails is given and $\S 5$ gives conclusions.

\section{Physical properties of irregularities}

During September 1975 to August 1976 radio beacon signals were received at Ootacamund (Lat. $11 \cdot 4^{\circ} \mathrm{N}$, Long $76.7^{\circ} \mathrm{E}$, dip $6^{\circ} \mathrm{N}$ ) using the geostationary satellite ATS-6. Amplitude measurements of 40,140 and $360 \mathrm{MHz}$ carrier waves carried out to investigate characteristics of ionospheric irregularities. During this one-year period, many events of isolated (ringing) ionospheric irregularities were observed. The depths and widths of ringing irregularity signatures as seen on amplitudes of 40,140 and $360 \mathrm{MHz}$ radio beacon signals radiated from ATS-6 recorded at Ootacamund have been measured and processed to yield ranges of electron density enhancements and scale sizes of the irregularities. The basic approach for these computations is that used by Heron (1976) and Trivedi et al (1978). The graphical relationship between the depth of the recorded pattern and the irregularity scale size is, however, different from that given by Heron (1976); the latter having been computed for a $300 \mathrm{~km}$ irregularity height.

The results of the model calculations show that a considerable majority of the irregularities which were observed $(\approx 90 \%)$ have values of scale sizes $d$ ranging from $50 \mathrm{~m}$ to $300 \mathrm{~m}$ and that of maximum possible electron density enhancements $\Delta N_{0}$ ranging between $5 \times 10^{11} \mathrm{el} / \mathrm{m}^{3}$ to $4 \times 10^{12} \mathrm{el} / \mathrm{m}^{3}$. 


\section{Properties of meteor trails}

Meteors are small bodies, most of them orbit around the sun. When a meteor enters earth's atmosphere it burns out due to the friction in the upper atmosphere and produces an intense column of ionisation and light. This effect has been observed and reported since 1920 (Skellet 1931). In general the effects noted are those associated with reflection of radio frequencies causing 'bursts" of received signals of a few minutes duration at the time when no reflection from $F$ layer is observed and occasional short periods of strong absorptions (Pierce 1938). The maintenance of increased general level of ionisation at the altitude of the $E$ layer during major meteor showers has also been attributed to meteors (Mitra et al 1934; Bahr 1937). The entry velocity of meteors lies between 11 and $72 \mathrm{~km} / \mathrm{sec}$. Typically a meteor travelling at a velocity $\geqslant 40 \mathrm{~km} / \mathrm{sec}$ possesses sufficient energy to produce a column of ionisation $30 \mathrm{~m}$ to $1 \mathrm{~km}$ in diameter. The line ionisation density varies from $10^{9}$ to $10^{18} \mathrm{el} / \mathrm{m}$ (Skellett 1935). Meteoric ionisation occurs mainly at altitudes between $80 \mathrm{~km}$ and $160 \mathrm{~km}$, with a maximum around $115 \mathrm{~km}$ (Appleton and Piddington 1938). These observations further indicate the existence of marked ionisation clouds in the ionosphere which form and disappear through the day. Maximum ionisation occurs immediately after the trail has been formed, the trail then begins to expand due to diffusion and as a result electron density decreases with time. During the course of its expansion it also bodily moves due to winds in the upper atmosphere. Such clouds or trails of ionisation are capable of producing the diffraction patterns shown in figure 1. Theoretical calculations to evaluate physical properties of this diffraction pattern have been carried out using a slant height of $152 \mathrm{~km}$ and show (figure 1b) excellent agreement with observed patterns.

\section{Comparison of RI and meteor showers}

In this section ringing irregularity events have been investigated in conjunction with earlier meteor data. Figure 2a shows the days on which known meteor showers occur (Whipple and Hawkins 1959; Millman and Mckinley 1963). These have been shown by rectangular blocks. The dots show the days on which RI are observed. It is shown that most of the RI occur on meteor shower days except during the months of January and February. It is to be noted that the rectangular blocks indicate only known meteor shower days as observed at high latitudes. It is quite likely that the RI during January and February might have been caused by the sporadic meteor showers since there are no known meteor showers in these months. One example of sporadic meteor shower is Dhajala meteorite which fell on 28 January 1976 in Gujarat (Lal and Trivedi 1977). It is interesting to note that from the middle of September to the middle of December there are many days with overlapping meteor showers. This period is associated with intense occurrence of RI.

It is known through earlier investigations (Mckinley 1961; Vogan and Campbell 1957) of meteor by radar and optical techniques that meteor occurrence rate is maximum during morning hours. This is attributed to the fact that the earth is moving in its orbit at $30 \mathrm{~km} / \mathrm{sec}$ and hence on forward side (sunrise side) of earth will encounter more meteors, than those in the evening hours.

The diurnal occurrence of hourly meteor rates for northern high latitudes is shown 

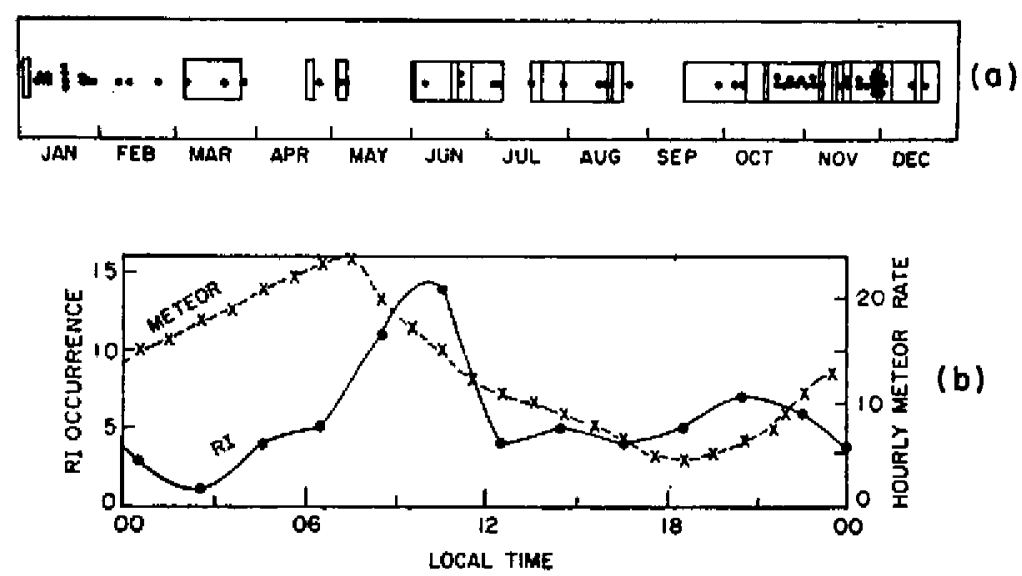

(b)

Figure 2 a. Days on which meteor showers (rectangular blocks) and ringing irregularities (dots) occur (meteor shower data from Whipple and Hawkins 1959, Millman and Mckinley 1963). b. Diurnal variation of hourly meteor occurrence and ringing irregularities (meteor data from Mckinley 1951).

in figure $2 \mathrm{~b}$. The data for meteor trails were collected by backscatter radar observations of 100,000 echoes. This curve indicates maximum occurrence of meteors around $0730 \mathrm{hr}$ local time and a broad minimum around $1800 \mathrm{hr}$ (Mckinley 1951). Diurnal radio meteor rates were also estimated by VHF forward scatter technique (Srirama Rao et al 1978) between Dehra Dun and Waltair in India for the period December 1974 to November 1975. This link looks at the ionosphere around $25^{\circ} \mathrm{N}$ latitude. The diurnal variation trend was found to be maximum around $0600 \mathrm{hr}$ local time and a minimum around $1800 \mathrm{hr}$ local time. The observations also showed a sharp fall in the meteor rates in the post-sunrise hours with a minimum around $0800-0900 \mathrm{hr}$ local time which was attributed to sharp rise in absorption of the VHF radio waves caused by rapid rise in $\mathrm{O}^{+}$ionisation in the $D$-region. The above results show a peak diurnal meteor rate between 0600 and $0730 \mathrm{hr}$ local time.

Figure $2 \mathrm{~b}$ aIso shows diurnal occurrence of RI. The RI observations were collected for one year beginning September 1975 and show a maximum at $1000 \mathrm{hr}$ with a delay of $2 \frac{1}{2} \mathrm{hr}$ compared to that of the meteor curve. It is worthwhile to note that the peak time in meteor occurrence varies by about $3 \mathrm{hr}$ depending on the technique (Mckinley 1951; Vogan and Campbell 1957). In addition the meteor echo observations and RI observations are taken during different epochs. Current observations on RI were made near the equator $\left(10^{\circ} \mathrm{N}\right.$ lat.) whereas meteor observations are available around $40^{\circ} \mathrm{N}, 25^{\circ} \mathrm{N}$ and $40^{\circ} \mathrm{S}$ latitudes. There is a reasonably good agreement between $\mathrm{RI}$ occurrence and hourly meteor rate.

In figure $3 \mathrm{~b}$ the seasonal variation of meteor occurrence around $40^{\circ} \mathrm{N}$ latitude shows a maximum around July-August and a broad minimum around February. The observations were made by Keay (1963). In the southern hemisphere the meteor occurrence rate is opposite to that in the northern hemisphere though their magnitude is very small. Note that the ordinate for southern hemisphere data is multiplied by 12 (Keay 1963).

Using meteor forward scatter propagation link at $48 \cdot 2 \mathrm{MHz}$ between Dehra Dun and Waltair, Srirama Rao et al (1978) reported that the mean monthly meteor rate has a minimum in February and maximum in October with a secondary maximum in 


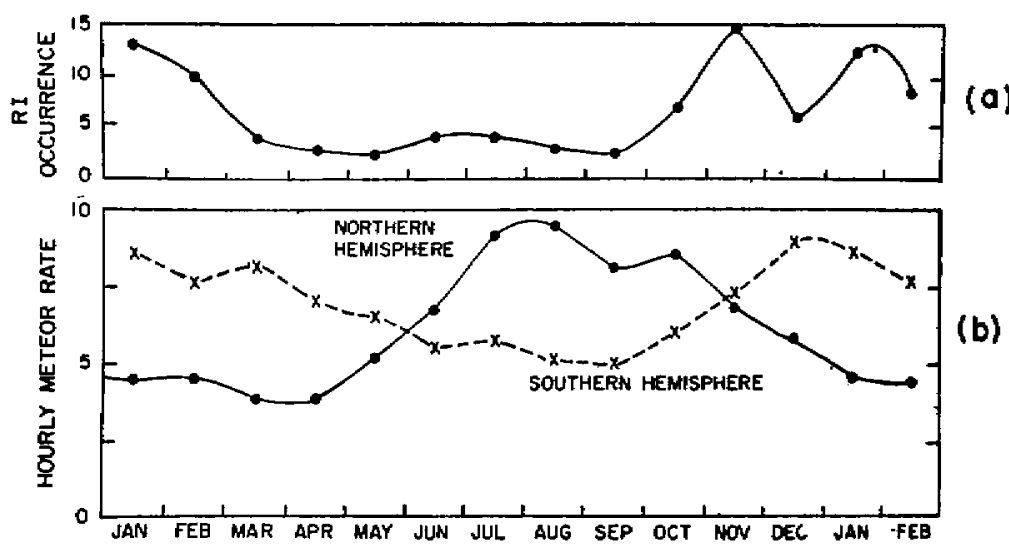

Figure 3 a. Occurrence of ringing irregularities during different months. b. Occurrence of hourly meteor rate in northern and southern hemisphere. Note that the ordinate of southern hemisphere is to be divided by 12 (meteor data from Keay 1963).

June. Further, they reported that there is steady rise from February to October and a rapid fall after that. Our results shown in figure 3a seem to agree to a large extent with those of Srirama Rao et al (1978), but not with those of Keay (1963). There is a minor difference between our results and those of Srirama Rao et al (1978) in that the earlier one (RI) shows a double peak during October to December.

\section{Conclusions}

Based on diffraction patterns produced on the ground by isolated ionospheric irregularities (ringing irregularities - RD the physical properties of these irregularities such as density, size etc. can be evaluated. These properties resemble with those of meteor ionization trails. In view of this a hypothesis on the origin of these RI has been proposed. It is suggested in this hypothesis that meteor ionisation trails are responsible for producing these RI. The diurnal and seasonal patterns of $\boldsymbol{R I}$ and those of meteor trails strongly support the above hypothesis. The diurnal meteor occurrence shows uniform behaviour over the globe with a maximum during early hours of the day; whereas there seems to be a strong latitudinal dependence of seasonal variation of meteor showers over the globe.

\section{Acknowledgements}

Grateful thanks are due to Professors K R Ramanathan, D Lal, S P Pandya and R G Rastogi for their encouragement during the course of this work. ATS-6 Ootacamund project was a joint undertaking of PRL and NOAA and the authors wish to thank Professors K Davies and G Swarup for collaboration and facilities respectively. This project was partially supported by DOS and NASA. Discussions with Drs N Bhandari, R V Bhonsle, H Chandra, D K Chakrabarty and Mrs P Chakrabarty have been greatly useful. Thanks are also due to Miss Chhaya R Shah for her help 
in data analysis. One of the authors (AIT) received financial support from CSIR, New Delhi.

\section{References}

Appleton E V and Piddington J H 1938 Proc. R. Soc. London A164 467

Bhar J N 1937 Nature, London 139470

Davies K and Whitehead J D 1977 J. Atmos. Terr. Phys. 39383

Elkins T J and Slack F F 1969 J. Atmos. Terr. Phys. 31421

Heron M L 1976 J. Atmos. Terr. Phys. 381027

Ireland W and Preddy G F 1967 J. Atmos. Terr. Phys. 29137

Keay C S L 1963 R. Astron. Soc. Mon. Not. 126165

Lal D and Trivedi J R 1977 Proc. Indian Acad. Sci. A86 393

Mckinley D W R 1951 Astrophys. J. 113225

Millman P M and Mckinley D W R 1963, The moon, meteorites and comets eds B M Middlehurst and G P Kuiper (Chicago: Univ. of Chicago Press) p. 674

Mitra S K, Syam P and Ghose B N 1934 Nature, London 133533

Pierce J A 1938 Proc. IRE 26892

Skellet A M 1931 Phys. Rev. 371668

Skellet A M 1935 Proc. IRE 23132

Srirama Rao M, Raja Ratnam S, Krishnarao D A V, Ramachandrarao B and Bhagiratha Rao E 1978 Space Sci. Symp. Abstracts, Physics Department, Andhra University, Waltair p. 2.2.3.

Titheridge J E 1971 J. Atmos. Terr. Phys. 3347

Trivedi A I, Deshpande M R and Vats Hari Om 1978 Proc. Indian Acad. Sci. A87 165

Vogan E L and Campbell L L 1957 Can. J. Phys. 351176

Whipple F L and Hawkins G S 1959 Handbuch der Phys. 52, ed. S Flugge (Berlin: Springer Verlag) p. 519 